\title{
River Pollution and Waste Waters from the Milk Industry
}

\author{
By Dr. A. Parker
}

$\mathrm{D}^{\mathrm{T}}$ URING recent years, the problems of treatment and disposal of the waste waters from the milk industry have increased in importance with the development of the industry in England and the establishment of depots and factories each receiving milk from many farms. Serious pollution of rivers and streams and difficulties at sewage disposal works in many parts of the country have been caused by discharges of waste waters from milk collecting and distributing depots and from factories making cheese, butter, condensed milk and other milk products. About four years ago, an investigation of the various problems was begun by the Water Pollution Research Board of the Department of Scientific and Industrial Research. Though the investigation has not yet been completed, it has already provided results of considerable practical value. It is the purpose of this article to give a brief description of those results.

In attempting to solve any problem of treatment and disposal of trade waste waters, the first step should always be to consider the practicability, taking costs into account, of so modifying the manufacturing processes that the wastes need not be produced or that the polluting matter carried away in the wastes is greatly reduced in quantity. Methods of purification of waste waters should only be considered after all practicable modifications in the factory processes have been adopted to reduce the polluting character of the wastes or to re-use the waste waters in the factory. Frequently the polluting character of the waste waters can be reduced by reducing losses of valuable material in the factory, or by recovering products or byproducts of value. This is the first line of attack which has been followed in the Water Pollution Research Board's investigation of the problem of pollution by the waste waters from the milk industry.

The investigation has shown that even at milk collecting and distributing depots, where the milk is received only for cooling, pasteurizing and distribution, the waste waters from washing delivery churns, coolers, pasteurizers, tank wagons, other equipment and the floors usually carry away $0.5-1.0$ per cent of the milk received. This means that the waste washing waters from a collecting and distributing depot handling 10,000 gallons of milk a day usually contain 50-100 gallons of whole milk. The volume of waste washing water in relation to the volume of milk handled varies considerably at different depots. If the volume of washing water is about the same as the volume of milk handled, 10,000 gallons of milk a day received in a collecting and distributing depot give rise to 10,000 gallons of waste water containing $0.5-1 \cdot 0$ per cent of milk. As measured by the test for dissolved oxygen taken up from aerated water in five days, water containing 1 per cent of whole milk has a biochemical oxygen demand of about 120 parts per 100,000 parts. Average domestic sewage has a biochemical oxygen demand of 40-50 parts per 100,000 , and the volume of domestic sewage is usually about 25 gallons a day per head of the population. A volume of 10,000 gallons a day of waste water containing 1 per cent of milk is thus equivalent in its de-oxygenating or polluting effect on a stream to the domestic sewage from a population of about 1,200.

From factories making cheese, butter, condensed milk and other products, in addition to washings from delivery churns, there are waste waters from washing cheese vats, butter churns, evaporators and other equipment. Even when care is exercised to reduce the losses of milk, of the main products and of the by-products whey, buttermilk and skim milk, the waste washing waters from cheese and butter factories contain organic matter equivalent to at least 2 per cent of the milk handled. At many factories the waste washing waters from the manufacture of cheese and butter contain organic matter equivalent to 3-4 per cent of the milk handled, and as much as 6-8 per cent has been found at some factories.

In the past, some factories have considered whey and buttermilk as waste materials and have discharged them into the nearest stream, with disastrous polluting effects. Whey has a biochemical oxygen demand of $4,000-5,000$ parts per 100,000 , so that it is approximately a hundred times as strong in polluting character as an equal volume of crude domestic sewage. In other words, if the whole of the whey from a cheese factory handling 10,000 gallons of milk a day were discharged into a stream, its polluting effect would be about the same as that of the crude domestic sewage from a town with a population of 40,000 50,000 people. Whey and buttermilk should be treated as valuable by-products, not as waste materials. They have high food values and can be utilized as food or in the preparation of foods. There is a market for dried whey and buttermilk, and there is no doubt that this market can be further developed. 
From the Water Pollution Research Board's investigation, it has definitely been concluded that the quantities of polluting matter carried away in the waste waters from the various branches of the milk industry can be considerably reduced by simple and inexpensive modifications in the operations within the factories, and by more careful control of the processes of draining and washing. At most depots and factories, the delivery churns are rapidly emptied and insufficient time is allowed adequately to drain the churns before they are transferred to the washers. By installing a simple drainage rack with a milk collecting-channel beneath and allowing the churns to drain on the rack for one or two minutes, the quantity of milk carried away in the water used for washing the churns can be reduced from more than 0.5 per cent to less than $0 \cdot 25$ per cent of the milk handled.

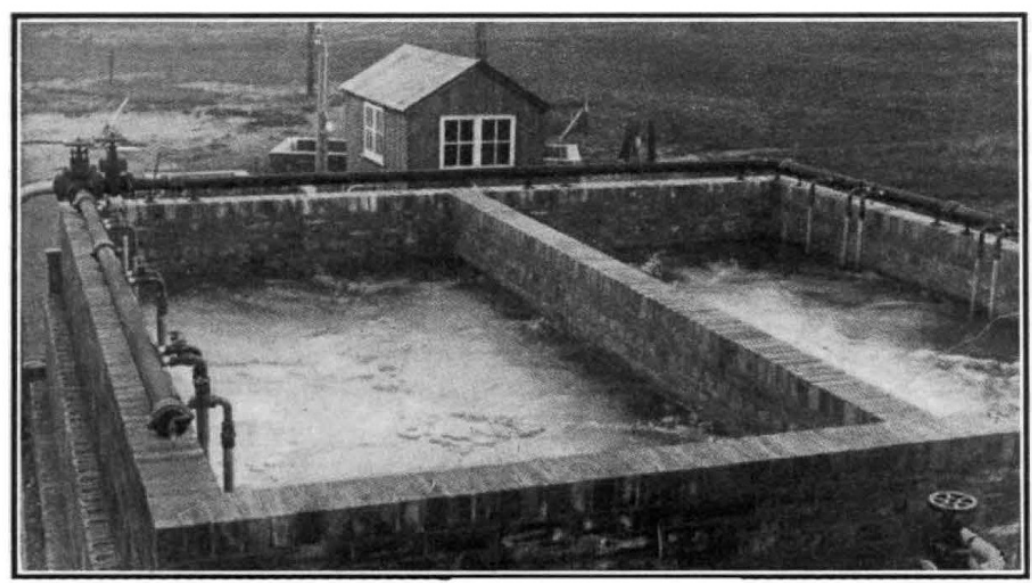

Fig. 1.

AERATion tanks OF EXPERIMENTAL PLANT FOR THE TREATMENT OF MILK EFFLUENTS BY THE ACTIVATED SLUDGE PROCESS.

Reproduced by permission of the Controller, H.M. Stationery Office; Crown copyright reserved.

This saving has definitely been effected at a large factory. It represents a saving of about 10,000 gallons of milk or $£ 750$ per annum, with milk at 1s. $6 d$. per gallon, for a collecting and distributing depot receiving an average quantity of 10,000 12,000 gallons of milk a day. If adequate drainage trays were installed at all the depots and factories in Great Britain, the total saving of milk would be roughly 3 million gallons per annum, or $£ 150,000$ per annum with milk at an average wholesale price for all purposes of $1 s$. per gallon.

Substantial improvements can usually be made also in the methods of draining and washing cheese vats, butter churns and other equipment to bring about considerable reductions in the quantities of whey, buttermilk and other products in the waste waters. Cheese vats and butter-churns, after the removal of whey and buttermilk, should first be washed with small quantities of water which should be added to the whey and buttermilk for use as food or for the preparation of foods. Subsequent washings with larger quantities of water would then contain much less polluting matter. Modifications of this kind not only cause direct savings in the factory but also reduce the size and the cost of construction and operation of the plant required for the treatment of the waste waters.

The next step in the investigation was to study possible methods of purifying the waste waters unavoidably produced. Plants in France and Belgium which were satisfactorily treating waste waters from condensed milk factories were visited. These plants utilize the activated sludge process according to the method devised by $\mathrm{H}$. Kessener of Holland. Experiments made in the laboratories of the Rothamsted Experimental Station for the

Water Pollution Research Board indicated that it would be practicable to purify the waste waters either by the activated sludge process or by the process of biological oxidation in percolating filters operated under certain conditions. In the experiments with percolating filters it was found that in single filtration, by the method normally employed in the treatment of sewage at sewage disposal works, solid matter was deposited in the top layers of the filter, which in consequence became choked and inoperative. It was found, however, that this difficulty could be overcome by adopting a method of biological filtration suggested by $\mathrm{H}$. C. Whitehead and the late F. R. O'Shaughnessy of the Birmingham, Tame and Rea District Drainage Board. By this method, the waste waters, after sedimentation to remove suspended solids, are passed through two biological filters in series, and the order of the two filters in series is changed at intervals of two or three weeks. Under suitable conditions, the partially treated effluent from one filter brings about the removal of the solid matter previously deposited in the top layers of the other filter, when this filter occupied the primary position.

With the financial co-operation of the industry, the investigation was extended to include experiments on a large scale at a cheese factory in Shropshire, where United Dairies Ltd. provided the necessary facilities. Through the Milk Marketing Board and the Scottish Milk Marketing Board, the industry has contributed nearly $£ 11,000$ 
towards the cost. Two large experimental plants were erected at the factory in Shropshire during the summer of 1935 . In one plant, the waste waters, after sedimentation, are treated by the activated sludge process (Fig. 1) operated in a manner similar to that adopted for the treatment of sewage at sewage disposal works. In the other plant (Fig. 2), the settled waste waters are submitted to biological oxidation in two percolating filters in series, and the order of the filters is reversed at intervals of ten days to three weeks. Each filter contains hard metallurgical coke, graded 0.75-1.5 in. Both plants have been in continuous operation since their erection in July 1935, in the treatment of milk washings and mixtures of milk washings and whey washings. For the activated sludge process, the settled crude waste is diluted, if necessary, to give a mixture parts per 100,000 parts. From this mixture a final effluent with a biochemical oxygen demand of less than 1 part per 100,000 parts is obtained, even with the high rate of treatment of 240 gallons a day per cubic yard of filtering medium in the two filters together, that is, $\mathbf{4 8 0}$ gallons a day per cubic yard in each filter. This is a rate of treatment much greater than that usually adopted in the treatment of domestic sewage at sewage disposal works in Great Britain. Tests over long periods have shown that trout are able to live in the undiluted final effluents from the experimental plants.

Of the two methods investigated for the treatment of milk effluents, the process of biological filtration with two filters in series and periodic change in the order of the filters appears to be the more suitable for operation under factory conditions. To allow a margin of safety, the diluted

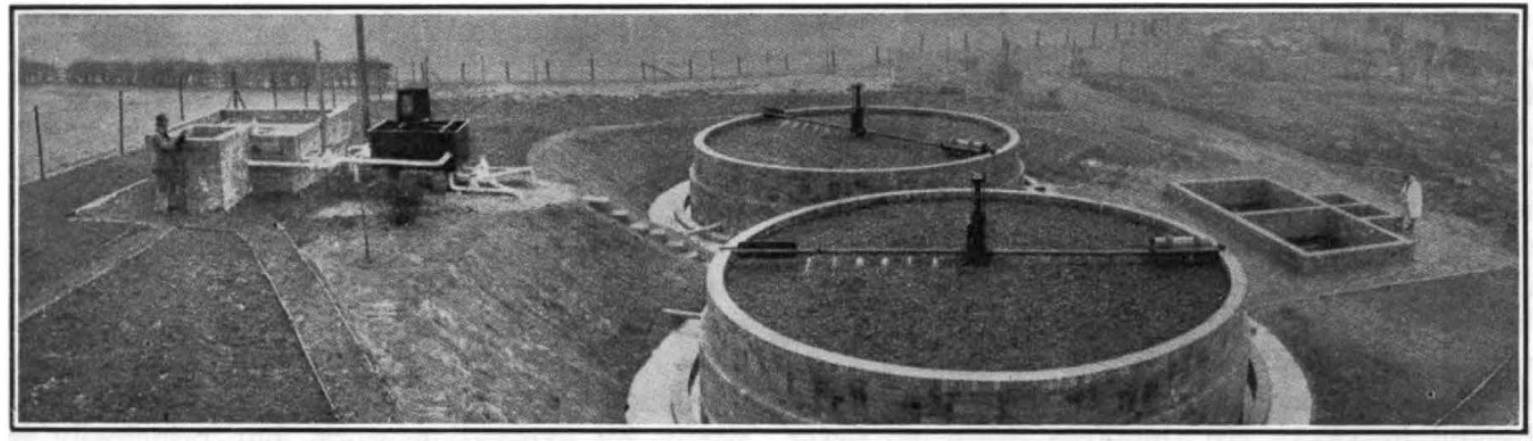

Fig. 2.

Experimental Plant for the treatment of MiLk efFluents by bIological filtration with two FILTERS IN SERIES.

Reproduced by permission of the Controller, H.M. Stationery Office; Crown copyright reserved.

with a biochemical oxygen demand of not more than 50 parts per 100,000 parts. From this mixture, with a period of aeration of twenty-four hours, a final effluent with a biochemical oxygen demand of about 1 part per 100,000 is obtained. For the biological filtration plant, the settled wastes are diluted to give a mixture with a biochemical oxygen demand of not more than 30 sattled crude liquid should be supplied to the filters at a rate not greater than 160 gallons a day per cubic yard of filtering medium in the two filters together. Daring the past two years, several plants designed on the basis of the experimental filtration plant have been erected at depots and factories in different parts of the country, and other similar plants are in course of construction.

\section{New Aspects and Problems in Irish Archæology*}

$\mathrm{T}$ HE acquisitions of new archæological material by the National Museum of Ireland now represent a yearly increase forty times larger than that of ten years ago. The old-established collection of Irish antiquities contains an unusually high percentage of unlocalized or ill-localized specimens; but the National Museum is now

* Substance of the presidential address for 1937 by Dr. Adolf Mahr to the Prehistoric Society. Proc. Prehist. Soc., 3, 2, pp. 262-436 +7 plates (1937). building up a second collection, each object accurately located, which at least in numerical strength compares with the old one and will serve as a basis for distributional studies.

During the past five years, large-scale systematic excavations have been undertaken, which have contributed to the clarification of at least some of the most hotly contested problems in the archæology of Ireland. No comprehensive survey 